\title{
Heritage Building Information Modelling (HBIM): a review of published case studies
}

Conference or Workshop Item

Accepted Version

Ewart, I. and Zuecco, V. (2019) Heritage Building Information Modelling (HBIM): a review of published case studies. In: 35th CIB W78 2018 International Conference: IT in Design, Construction, and Management, 1-3 October 2018, Chicago, Illinois, USA, pp. 35-41. (ISBN 978303000220-6) Available at http://centaur.reading.ac.uk/79742/

It is advisable to refer to the publisher's version if you intend to cite from the work. See Guidance on citing. 
the End User Agreement.

www.reading.ac.uk/centaur

\section{CentAUR}

Central Archive at the University of Reading

Reading's research outputs online 


\title{
Heritage Building Information Modelling (HBIM): A review of published case studies.
}

\author{
Ian J. Ewart ${ }^{1}$ and Valentina Zuecco ${ }^{2}$ \\ ${ }^{1}$ School of the Built Environment, University of Reading, UK. \\ ${ }^{2}$ Dept. of Civil, Environmental and Architectural Engineering, University of Padova, Italy.
}

\begin{abstract}
.
Building Information Modelling (BIM) is gaining popularity worldwide as a system of collaboration and data management for the AEC sectors. However, the usefulness of BIM has largely been seen in the design and construction phases, rather than in post-construction - for example in facilities management or occupancy. As the concept of BIM has matured, there has been increasing interest in applying these concepts and technologies to heritage buildings (HBIM), despite some fundamental differences: heritage buildings usually have a long history of use, re-use and alteration; their management is often related to conservation rather than occupancy; and they are often a social and community resource. Therefore, HBIM is faced with a different set of stakeholders to 'standard BIM', which leads us to question the optimistic perceptions of its usefulness when BIM is applied to a historic built environment context.

We investigate this question by thinking about how we can characterise HBIM, and what sort of information will give us further insights. Using published case studies as a source of secondary data, we have collected information about specific characteristics, which we analyse and use to discuss the uptake of HBIM, the purpose of HBIM and the role of stakeholders. We conclude that there needs to be a significant change in perception of HBIM by academics and technicians, before it is likely to be adopted by practitioners in the heritage sector. ${ }^{1}$
\end{abstract}

Keywords: HBIM, BIM, Heritage Buildings, case studies

\section{Introduction: The Distinctive Nature of Heritage BIM}

\subsection{Perspectives on BIM}

While long recognised as a significant influence on the architecture, engineering and construction (AEC) sectors, descriptions and definitions of Building Information Modelling (BIM) have grown to include aspects of the lifecycle of a building beyond its design and construction. Typical of these is the National BIM Standard as quoted in ISO 29481-1:

"Building Information Modelling (BIM) is a digital representation of physical and functional characteristics of a facility. A BIM is a shared knowledge resource for

\footnotetext{
${ }^{1}$ This research was carried out as part of an Erasmus+ Student Traineeship between the Universities of Reading, UK and Padova, Italy. This allowed VZ to work on her Master's thesis, which forms the basis of this paper (Zuecco 2018).
} 
information about a facility forming a reliable basis for decisions during its life-cycle; defined as existing from earliest conception to demolition. A basic premise of BIM is collaboration by different stakeholders at different phases of the life cycle of a facility to insert, extract, update or modify information in the BIM to support and reflect the roles of that stakeholder."

Of note is the emphasis on collaborative working and the vision of BIM as a method that can be applied at all stages of the life of a building, as well as the lack of a specific mention of a 3D model as a pre-requisite of BIM. In particular, there is an important implication that the range of stakeholders is likely to be wide and varied, and that access to (and possibly also management of) digital data is a democratic process. Other definitions focus on the technologies of BIM (e.g. those of the US Government's GSA, Heritage Foundation Canada, and software suppliers such as Autodesk), especially the use of 3D models, often at the expense of downplaying the role of collaboration in the production and use of the system. Conversely, in a similar vein to the NBS quoted above, several authors and organisations have seen the collaborative aspects of BIM as the key tenet, and recognised some of the issues this exposes. In the UK, for example, the British Standards Institute is working to formulate and promote a set of standards to ensure digital data quality, and the American Institute of Architects aims to increase awareness of issues of interoperability through the BuildingSMART Alliance, for "the sharing and exchanging of information via integrated technological solutions, no matter what project phase, discipline or participant role in the built asset life cycle" (AIA 1997).

So, while the benefits of BIM are generally held to include reduced costs and errors, increased efficiency in planning and construction, collaboration in design and understanding, and more efficient facilities management, the published literature is heavily biased towards the design and construction phases of the building's life cycle (e.g. all the case studies in 'the BIM handbook' (Eastman et al. 2011)). Successful and widespread adoption of post-construction BIM is proving elusive, in part due to issues of interoperability and digital data standards, and how these clash with existing data and asset management systems, but also due to the different skillsets that are traditionally available to an FM manager, and the need for a cultural shift (Davies and Harty 2013). If applying BIM to finished buildings is proving difficult, then an extra layer of complexity becomes apparent when the same systems are applied retrospectively to older existing buildings, usually without native digital data, since much of the information is 'born analogue', or even basic information on structures and services that would be required to construct a comprehensive and useful dataset (Bryan and Antonopoulou 2017).

\subsection{Understanding HBIM}

'HBIM' (as Historic Building Information Modelling) was first mentioned in 2009 and defined as "a novel solution whereby interactive parametric objects representing architectural elements are constructed from historic data, these elements (including detail behind the scan surface) are accurately mapped onto a point cloud or image-based survey" (Murphy et al. 2009:311). The term has since been broadened to include the 
heritage environment generally, recognising a more complex set of historic and aesthetic values and the involvement of multiple stakeholders and disciplines.

Heritage has a social value for individuals and communities but there are national and regional differences in evaluating heritage status and value. The north European concept of heritage is wider than for example in Italy, meaning a broad idea that records and expresses the long processes of historic development, as social reference point and a contribution to local identity. It is defined by English Heritage as "all inherited resources which people value for reasons beyond mere utility" (Drury and McPherson 2008:71). This definition includes more than just physical features, and even buildings which are architecturally irrelevant or even no longer standing can be recognized as heritage for having had an historic role within the community in the past.

Since a heritage building is a distinct type of existing construction that involves facility management activities, HBIM appears to have the same potential as the implementation of BIM for the whole building lifecycle but also the same unresolved issues. Over and above the issues described above for a typical new or recent construction, a heritage building lacks a complex set of data that takes account of the history of construction, maintenance and reconstruction of all or part of the structure and services. In many cases the available information is insufficient to provide the basis for such a dataset. Furthermore, the distinct nature of heritage buildings as cultural and community resources raises the question of what data is useful, relevant and important to the building, to satisfy the needs of a wide range of stakeholders, or which of those stakeholders should be omitted from consideration? As well as the owners, occupants and facilities managers of a typical building, there are other stakeholders such as visitors, historians, researchers, students, heritage organizations, local government and the local community. In cases of building intervention architects and engineers may cooperate with surveyors, archaeologists, conservationists and academics.

Applying BIM to heritage buildings seems to be an opportunity to mobilise a proactive approach to management and conservation of the construction and its community value. BIM can provide a set of information useful for FM tasks such as condition monitoring, preventive maintenance, repair and restoration, but also for the management of visitors and related security and safety planning. Moreover, the Information Model could be a resource for many or all of the stakeholders interested in the historic and social value of the building, as well as supporting further studies. However, this potential is largely illusory as "the effective use of BIM is far more complex than new build and the benefits less obvious” (Brookes 2017:19). To date, the majority of recent research has focused on the technical challenges of producing accurate 3D models, rather than investigating the wider application of HBIM and resolving some of the softer issues described above.

Currently there is no comprehensive overview of HBIM case studies in the published literature, but a review of BIM for existing buildings was carried out in 2014 including papers reporting on heritage buildings (Volk et al. 2014). That study confirmed that the available literature tends to cover only a few topics, especially technical challenges such as automated data extraction, whereas issues beyond the modelling stage were largely unconsidered by academics at that time. 


\section{Methodology: A Case Study Database}

To offer some insights into the application of BIM tools and techniques to the heritage sector, the authors carried out a systematic literature search to identify any published case studies and analyzed the content (Zuecco 2018). The aim was to understand what BIM for heritage currently means, so the research papers deemed eligible for the case study database were the ones that claimed to be examples of BIM for heritage, historic or existing buildings, regardless of whether they effectively used a BIM process or not. We did not include publications that discussed the application of BIM to heritage in an abstract way, but included only those that described an actual example of the application of BIM to a physical building. This was not restricted to the use of the term 'BIM' specifically, but also included any BIM-like methods of digital data management and control.

A comprehensive literature search of the main academic sources was conducted, using specific keywords that were adjusted according to the keywords used on each eligible publication. These were primarily: BIM, HBIM, heritage, historic, digital, archaeology, cultural, restoration, conservation, reconstruction, maintenance. During the search process it became clear that Italy is a prominent advocate of HBIM, so equivalent searches were carried out in Italian (one of the authors, VZ, is Italian). With very few exceptions, the publications reported on academic or research projects; the remainder were from industry, and usually the result of support from suppliers of hardware or software. This research ended in October 2017 at which time the database contained fifty-two case studies.

Data from each case study was extracted to examine both the object of study the building or site studied - and the methods and results of the BIM process as reported by the authors. This resulted in 27 data variables in two sets (see Table 1 below), one relating to the building data and one relating to the publication data, for each of the 52 case study ID numbers. The variable data ranged from simple binary responses (e.g. was additional data attached to the model? Yes/No), to multiple responses (e.g. 12 different results to 'what was the purpose for creating the HBIM model?')

Table 1: Variables extracted from each case study

\begin{tabular}{llll}
\hline \multicolumn{2}{c}{ Building Data variables } & \multicolumn{2}{c}{ Publication Data variables } \\
\hline Object type & Listing status & Keywords & Plug-ins \\
Country & Conservation status & Purpose & Data added \\
City & Original use & Stakeholders & Data type \\
Size & Current use & Type of survey & Data exported \\
Area & Access to public & Survey software & Other software \\
Accessibility & Construction year & Modelling software & Publication year \\
Ownership & \multicolumn{2}{c}{ New component } & HBIM useful? \\
& & families required? & \\
\hline
\end{tabular}




\section{Analysis and Discussion}

\subsection{Introduction}

A comprehensive presentation and discussion of the results of this analysis is in preparation, but we are able to offer some preliminary insights here. Considering the 27 variables for each of the 52 identified case studies, and with between 1 and 12 responses for each variable, the resulting database can be divided up, combined, and analyzed in a number of ways. As mentioned above, a more detailed analysis is in preparation, but after an initial review of the data we are able to present three points of discussion that offer some basic but interesting insights, which we will expand upon in the near future: uptake of HBIM; purpose of HBIM; and HBIM stakeholders.

\subsection{Trends in the uptake of HBIM}

As discussed in the introduction, BIM has had a generally positive reception, especially among the academic and policy-making communities, and has been adopted with little resistance in the AEC sector. It has made fewer inroads as a technology into the postconstruction phases of the life of a building, although in many ways the philosophy of BIM as collaborative and accessible data management is ingrained within the working practices of many FM professionals. It is this disconnect between existing philosophies of practice and suspicions about the need for digital tools and skills that is halting general acceptance. The specific requirements of the heritage sector exacerbate those issues: funding is even more limited, the skillsets of the stakeholders are less aligned with recent digital technologies, and the needs of the stakeholders are even wider. Therefore, it is no great surprise that the uptake of HBIM appears to be relatively slow.
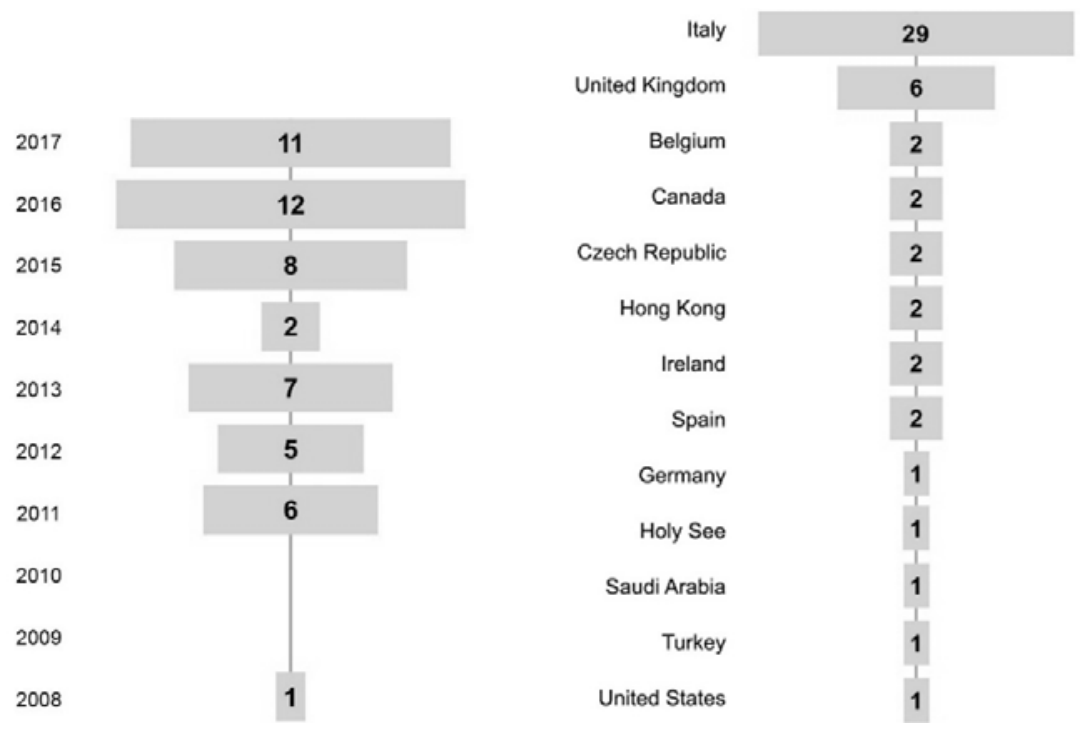

Figures 1a and 1b: Number of case studies per year and per country. 
If we are correct in assuming that our database is sufficiently comprehensive to be representative of the actual use of HBIM, then there has been a fairly gradual increase in the last decade, but by no means an exponential growth. Similarly, Figures 1 (above) and 2 (below) show that the reported use of HBIM is not only increasing gently, but is also localized, particularly in Europe and especially in Italy. Furthermore, many of the non-European case studies have been carried out by European researchers, with the same individuals appearing repeatedly as authors.

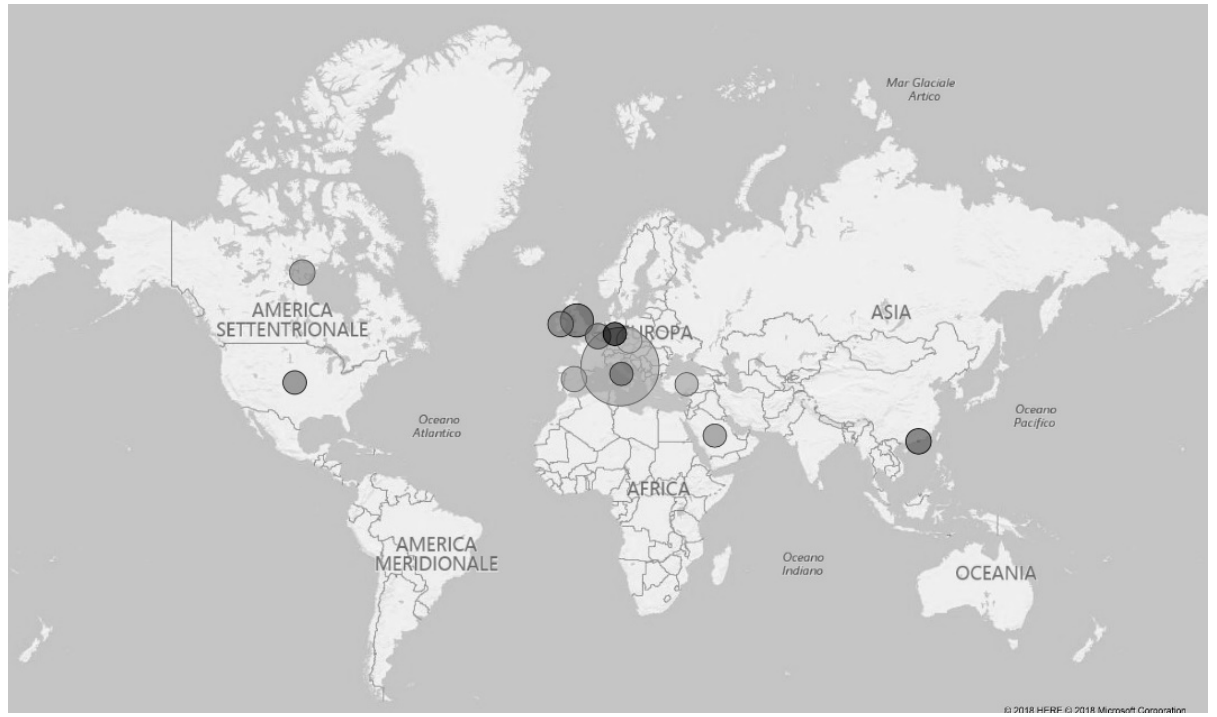

Figure 2: Case study locations by country (circle size = no. of case studies)

\subsection{The Stated Purpose of HBIM Systems}

As a relatively new method and technology, BIM has been undergone something of an explosion in interest in the last decade - the so-called BIM-boom was widely reported and predicted in many construction industry journals. From the beginning the main point of BIM was the management of a comprehensive digital dataset in a way that allowed collaborative working. As tools and technologies developed, so did the possible uses including for example 3D, 4D and even 5D models, and everything from LEED to disaster planning (e.g. Shou et al. 2015)

However, while this demonstrates the potential for use, it does not reflect actual working practices. In fact, it may be seen as a consequence of the confusion that still surrounds the purpose of BIM, with different practitioners 'doing BIM' in very different ways (Dainty et al. 2017) To evaluate the perception of BIM when applied to heritage buildings, we extracted from the case studies a summary of the stated purpose for carrying out the work. While this is in some ways a subjective judgement, especially as almost none of the case studies explicitly defined their aim, we narrowed down the wide variety of implied purposes to a list of 12 (See Table 2 below). 
Table 2: Stated purpose of HBIM case study.

\begin{tabular}{|c|c|c|c|c|c|c|c|c|c|c|c|}
\hline Purpose & $\begin{array}{l}\infty \\
\stackrel{ᄋ}{\circ}\end{array}$ & ஓ् & $\stackrel{\circ}{\stackrel{ }{\circ}}$ & $\overrightarrow{\widetilde{\sigma}}$ & $\underset{\sim}{\stackrel{乛}{\circ}}$ & $\stackrel{m}{\stackrel{\infty}{\circ}}$ & 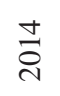 & $\stackrel{\text { ㅁ }}{\sim}$ & $\begin{array}{l}0 \\
\stackrel{\sigma}{\circ}\end{array}$ & $\vec{尺}$ & స్ㅠㅁ \\
\hline Testing BIM for heritage & 1 & & & & 1 & 2 & & 3 & 6 & 2 & 15 \\
\hline Planned conservation / FM & & & & 1 & 2 & 3 & 1 & 4 & 1 & 7 & 19 \\
\hline Archaeological/Architectural studies & & & & 4 & 1 & 1 & 1 & 1 & 4 & & 12 \\
\hline Restoration project & & & & 1 & & 2 & 1 & 3 & 2 & 3 & 12 \\
\hline Representing historical stages & & & & 1 & 2 & 2 & & 1 & 1 & 2 & 9 \\
\hline Valorization of heritage & & & & & 1 & 3 & 1 & 1 & 5 & 3 & 14 \\
\hline Energy/Wind/Sunshine analysis & & & & & 2 & 1 & & 2 & & 2 & 7 \\
\hline Degradation analysis & & & & & 1 & & & 3 & 1 & 1 & 6 \\
\hline Structural analysis & & & & & 1 & & & 2 & & 3 & 6 \\
\hline Virtual Reality & & & & & 1 & & & & & 1 & 2 \\
\hline 3D printing & & & & & & 1 & & & 1 & & 2 \\
\hline Unknown & & & & & & & & & & & $\mathbf{0}$ \\
\hline
\end{tabular}

From this we can see that there is no distinct purpose or trend that helps to answer the question 'why did you do this case study?' Of those that were most clear about their purpose, the three most common are the use of HBIM for conservation; an academic exercise to test the workflow; and as a tool to valorize, or ascribe value to the building studied. And, reflecting some of the enthusiasm for BIM, these case studies do not claim to have actually achieved their loosely stated purpose, they are instead describing the potential uses of HBIM.

\subsection{Stakeholder Involvement and Responses}

Of particular interest, and informed by the apparent confusion about the role of HBIM (and it could be argued, of BIM also), is the degree to which stakeholders are recognised as an important part of the technology and philosophy of BIM. As shown in Table 2 (above) the published case studies imply that there are a number of potential purposes for HBIM, but they remain, at present, apparently unfulfilled. For the authors of the published case studies, their potential purposes are linked to imagined stakeholders, such as the claim that a HBIM system could "...serve as the basis for future conservation and rehabilitation of the structure [and] can benefit the restoration, conservation, and management of this important heritage building as well as contribute to an integrated record of the more intangible aspects of the construction process" (Fai et al. 2013:119). 
Table 3 - Stakeholders discussed in case studies.

\begin{tabular}{lclc}
\hline Stakeholder & Total & Stakeholder & Total \\
\hline Unknown & 28 & Facility managers & 4 \\
Conservationist, architects & 11 & Heritage organisations & 3 \\
Students, researchers, historians & 10 & Local governments & 3 \\
Visitors & 6 & Occupants & 0 \\
Owner & 4 & Archaeologists & 0 \\
\hline
\end{tabular}

Invoking these imaginary target audiences gives HBIM a cloak of usefulness, but in truth there is little to suggest that the diversity of stakeholders inherent in a heritage site have been seriously considered as part of these case studies (see Table 3 above). The list of stakeholders we have produced, based on the content of the publications, is by no means exhaustive, and yet it still goes to show the diversity of uses that HBIM could serve. These are potential users of an HBIM system, each with their own requirements for data and means of access; a facilities manager for example would have very different needs to a local historian. It is worth noting that the largest proportion of all stakeholders identified in all case studies is 'unknown', that is, in more than half the case studies there is no mention of stakeholders.

We can see a similar picture in a final piece of data from our analysis, which was an assessment of whether the HBIM system was deemed a success. The two figures below (4a and $4 \mathrm{~b}$ ) show that the vast majority (96\%) of the authors of the publications (and usually also the systems) viewed it favourably, in fact none of the studies reported negative feedback. On the other hand, the opinion of other stakeholders (apart from the authors) is unknown in the vast majority of cases (90\%), and of those whose evaluation of the HBIM system was reported, in all cases the stakeholders were less enthusiastic than the authors.

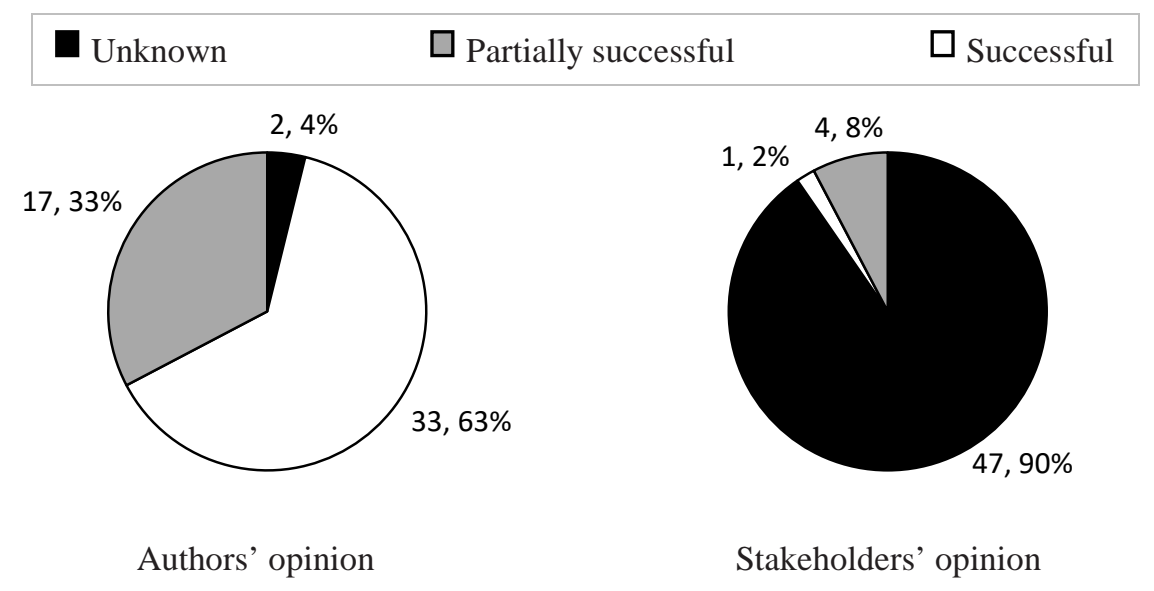

Figures $\mathbf{4 a}$ and $\mathbf{4 b}$ - Opinions as to the success of the HBIM system produced. 


\section{Conclusions}

Our study shows that there is a slowly growing suggestion that BIM could be usefully applied to heritage sites and buildings, especially in Europe. The cases we report on here all try to apply existing BIM workflows to their highly varied examples, and report a very high degree of satisfaction with their results. This is despite the widely reported distinctive requirements for a heritage site, in particular the extent and condition of standing buildings or remains of buildings, an expanded range of stakeholders to acknowledge the social importance of heritage sites, and the complexities of conservation and historic change. We can also note the lack of a clearly defined purpose or structure for a HBIM system, and the absence of any evidence that the reported potential uses for such a system have actually been realized. The majority of these cases are primarily interested in solving technical challenges, in particular ever more accurate 3D models of complex structures, without reflecting seriously on the needs of the presumed stakeholders.

It would therefore be perhaps somewhat harsh, but apparently true to say that this study suggests that we do not know what HBIM is, who it is for, or why it would be used, but it is gaining popularity among academics and industry technicians in the hope that resolving technical issues will make it a practical proposition to the heritage sector generally.

\section{References}

American Institute of Architects: Document B141. Standard Form of Agreement Between Owner and Architect with Standard Form of Architect's Services. AIA, Washington DC (1997)

Brookes, C.: The application of building information modelling (BIM) within a heritage science context. Discovery Innovation and Science in the Historic Environment. Historic England Research Project Report no.7351 (2017). ISSN2398-3841.

Bryan, P. and Antonopoulou, S.: BIM for Heritage: Developing a historic building information model. Historic England, Swindon (2017).

Dainty, A., Leiringer, R., Fernie, S., and Harty, C.: BIM and the small construction firm: a critical perspective. Building Research \& Information, 45 (6), 696-709, (2017). DOI: $10.1080 / 09613218.2017 .1293940$

Davies, R. and Harty, C.: Measurement and exploration of individual beliefs about the consequences of building information modelling use. Construction Management and Economics, 31 (11), 1110-1127 (2013).

Drury, P. and McPherson, A.: Conservation Principles, Policies and Guidance. For the sustainable management of the historic environment. English Heritage, London (2008).

Eastman, C., Teicholz, P., Sacks, R. and Liston K.: BIM Handbook: A guide to building information modelling for owners, managers, designers, engineers and contractors. Wiley, Hoboken (2011). 
Fai, S., Filippi, M., and Paliaga, S.: Parametric modelling (BIM) for the documentation of vernacular construction methods: a BIM model for the commissariat building, Ottawa, Canada. ISPRS - Annals of the Photogrammetry, Remote Sensing and Spatial Information Sciences, 2 (5/W1), 115-120 (2013).

Murphy, M., McGovern, E. and Pavia, S.: Historic building information modelling (HBIM). Structural Survey, 27(4), 311-327 (2009).

Shou, W., Wang, J., Wang, X. and Chong, H.Y.: A comparative review of BIM implementation in building and infrastructure industries. Archives of Computational Methods in Engineering, 22, 291 (2015).

Volk, R., Stengel, J., Schultmann, F.: Building Information Models (BIM) for existing buildings - literature review and future needs. Automation in Construction, 38, 109-127, (2014).

Zuecco, V.: Implementing Building Information Modelling for heritage buildings and multiple stakeholders: literature overview and case study. Unpublished thesis, Università degli Studi di Padova (2018). 